\title{
Características do fluído ruminal de ovinos Santa Inês criados extensivamente em Pernambuco ${ }^{1}$
}

\author{
Aerlem Cynnara S. Vieira ${ }^{2 *}$, José Augusto B. Afonso ${ }^{3}$ e Carla L. Mendonça ${ }^{3}$
}

\begin{abstract}
Vieira A.C.S., Afonso J.A.B. \& Mendonça C.L. 2007. [Ruminal fluid characteristics of Santa Inês sheep under pasture conditions in the State of Pernambuco.] Características do fluído ruminal de ovinos Santa Inês criados extensivamente em Pernambuco. Pesquisa Veterinária Brasileira 27(3):110-114. Clínica de Bovinos, Universidade Federal Rural de Pernambuco (UFRPE), Cx. Postal 152, Garanhuns, PE 55292-901, Brazil. E-mail: acynnara@gmail.com

The objective of this study was to determine normal standards to ruminal fluid characteristics of Santa Inês sheep under pasture conditions in the State of Pernambuco. Fifty samples were collected, using an esophageal tube, during winter (rainy season) and summer (dry season). The predominant colors were an olive green in the rainy season and a nut-brown in the dry season. The smell was aromatic, but was stronger in winter. A slight viscous consistence was found in most of the samples, with a greater proportion in winter. The sedimentation and flotation time was $6.73 \mathrm{~min}$ $( \pm 1.63)$ in the rainy period and $3.15 \mathrm{~min}( \pm 0.72)$ in the dry period. In the biochemical tests, the average values found in winter and summer were, respectively: $\mathrm{pH} 6.76 \pm 0.21$ and 6,59 \pm 0.14 ; methylene blue reduction, $3.20 \mathrm{~min}( \pm 0.76)$ and $7.76 \mathrm{~min}( \pm 3.00)$; chloride, $28.14 \pm 4,16 \mathrm{mEq} / \mathrm{L}$ and $24.97 \pm 5.65 \mathrm{mEq} / \mathrm{L}$; acidity, $21.90 \pm 4.38 \mathrm{UC}$ and $13.68 \pm 2.97 \mathrm{UC}$. Ruminal microbiotic analyses revealed abundant and moderate density of protozoa in winter and summer, respectively. The motility was very active and there were almost $90 \%$ of live protozoa in both seasons. Protozoa numbers were $425.373 \pm 217.258 / \mathrm{mL}$ in winter and $155.375 \pm 83.113 / \mathrm{mL}$ in summer. There was a mixed population of bacteria with prevalence of Gram-negative forms in both seasons.
\end{abstract}

INDEX TERMS: Ruminal fluid, sheep, bacteria, protozoa.

RESUMO.- Este trabalho teve por objetivo estabelecer padrões de normalidade para as características do fluído ruminal de ovinos da raça Santa Inês criados sob regime extensivo de pastagem no município de Garanhuns, Agreste Meridional de Pernambuco. Foram coletadas amostras de 50 animais, por meio de sonda esofágica, nos períodos de inverno (estação chuvosa) e verão (estação seca). As cores do fluído predominantes foram a verde oliva, no período chuvoso, e a castanha, no período seco. O odor aromático foi observado em todas as amostras, estando mais pronunciado no inverno. A consistência levemente viscosa predominou em ambas as estações, com maior freqüiên-

\footnotetext{
${ }^{1}$ Recebido em 14 de agosto de 2006.

Aceito em 12 de fevereiro de 2007.

Parte da Dissertação do primeiro autor, apresentada ao Programa de Pós-Graduação em Ciência Veterinária, Universidade Federal Rural de Pernambuco (UFRPE).

2 Pós-Graduando em Ciência Veterinária, UFRPE, Recife, PE 52171-900. *Autor para correspondência: acynnara@gmail.com

${ }^{3}$ Clínica de Bovinos, Campus Garanhuns, UFRPE, Av. Bom Pastor s/n, Mundaú, Cx. Postal 152, Garanhuns, PE 55292-901. E-mail: carlaze@uol.com.br
}

cia desta no inverno. $O$ tempo de sedimentação e flotação foi de $6,73 \mathrm{~min}( \pm 1,63)$ na estação chuvosa e $3,15 \mathrm{~min}( \pm 0.72)$ na estação seca. Nas provas bioquímicas os valores médios encontrados para o inverno e verão, respectivamente, foram: $\mathrm{pH}$, $6,76 \pm 0,21$ e 6,59 $\pm 0,14$; redução do azul de metileno, $3,20 \mathrm{~min}$ $( \pm 0,76)$ e $7,76 \mathrm{~min}$ ( \pm 3.00$)$; teor de cloretos, $28,14 \pm 4,16 \mathrm{mEq} / \mathrm{L}$ e $24,97 \pm 5,65 \mathrm{mEq} / \mathrm{L}$; acidez total titulável, $21,90 \pm 4,38 \mathrm{UC}$ e $13,68 \pm 2.97$ C. Observou-se densidade abundante $(+++)$ de protozoários no inverno e moderada $(++)$ no verão. A motilidade dos protozoários foi bastante ativa $(+++)$ e havia aproximadamente $90 \%$ deles vivos em ambos os períodos experimentais. A contagem de protozoários no inverno foi de $425.373 \pm 217.258 / \mathrm{mL}$ e $155.375 \pm 83.113 / \mathrm{mL}$ no verão. As bactérias Gram-negativas predominaram em ambas as estações.

TERMOS DE INDEXAÇÃO: Fluído ruminal, ovinos, bactérias, protozoários.

\section{INTRODUÇÃO}

Os ruminantes estão em uma posição mais favorável em relação aos outros animais de produção, pois são capazes de uti- 
lizar a celulose e convertê-la em produtos assimiláveis, através da constante atividade fermentativa exercida pela população microbiana do rúmen (Eads 1997, Bacila 2003).

A produção animal, especialmente na região Nordeste Brasil, é limitada em parte pelos elementos climáticos e pelo manejo inadequado da produção de forragens. Na época de verão a escassez da oferta de alimentos é um fator limitante à produção, e induz a uma suplementação através de concentrados, elevando os custos de produção, alterando a composição da dieta e promovendo mudança dos hábitos alimentares, contribuindo desta forma para o surgimento de transtornos digestivos (Costa 1992, Andriguetto et al. 1999, Miranda Neto et al. 2005).

Neste contexto, as provas para avaliar as características do suco fluído ruminal juntamente com o exame físico do paciente assumem grande importância na avaliação dos problemas de ordem digestiva, auxiliando no diagnóstico e terapia a serem estabelecidas (Rings \& Rings 1993, Garry 2002).

No Brasil a ovinocultura vem crescendo a cada ano, mas os trabalhos para estabelecer valores de referência das características analisadas no fluído ruminal ainda são escassos, sendo necessárias pesquisas dessa natureza nas diversas condições de manejo e para cada região do país, visto que estes fatores influenciam e podem modificar os padrões de normalidade (Feitosa 1991, Souza \& Barcellos 1993, Simplício \& Wander 2003).

Com base nesses fatos, este trabalho teve por objetivo estudar as características do fluído ruminal em ovinos da raça Santa Inês criados sob regime extensivo de pastagem no Agreste Meridional do Estado de Pernambuco nas épocas de inverno (estação chuvosa) e verão (estação seca).

\section{MATERIAL E MÉTODOS}

O trabalho foi desenvolvido nas instalações da Clínica de Bovinos Campus Garanhuns, da Universidade Federal Rural de Pernambuco e as amostras foram analisadas no seu Laboratório Clínico.

Foram utilizados 50 animais, clinicamente saudáveis, da raça Santa Inês, adultos, entre machos e fêmeas, submetidos a regime extensivo em pasto formado por braquiária (Brachiaria decumbens) nas épocas de inverno (estação chuvosa) e verão (estação seca). Os animais receberam ainda capim-elefante (Penisetum purpureum) no cocho pela manhã e no final da tarde, tendo acesso à água e sal ad libitum.

As forragens foram analisadas para a determinação da matéria seca (MS), proteína bruta (PB) extrato etéreo (EE), e matéria mineral (MM) nas estações chuvosa e seca, de acordo com a AOAC (1990). Para as análises da fibra detergente neutra (FDN) e Fibra detergente em ácido (FDA) foi empregada à metodologia proposta por Van Soest et al. (1991).

As coletas foram realizadas uma vez em cada animal nos dois períodos experimentais, entre 4 a 6 horas após a alimentação matinal, sendo obtidos entre $300-400 \mathrm{ml}$ de fluído ruminal com auxílio de uma sonda esofágica semiflexível medindo $1,5 \mathrm{~m}$ de comprimento e $1 \mathrm{~cm}$ de diâmetro interno, tendo em uma das extremidades um bico metálico fenestrado e a outra acoplada a uma bomba de sucção artesanal e tubo coletor de vidro conforme descrito por Silva et al. (1994). Após serem colhidas as amostras eram acondicionadas em garrafas térmicas previamente aquecidas $\left( \pm 39^{\circ} \mathrm{C}\right)$.

A análise do fluído ruminal foi feita logo em seguida à coleta $\mathrm{e}$ abrangia a avaliação física da cor, odor, consistência, tempo de sedimentação e flotação (TSF). Dentre os aspectos bioquímicos foram averiguados o $\mathrm{pH}^{4}$, a redução do azul de metileno (RAM), o teor de cloretos (TC) e a acidez total titulável (ATT). Os protozoários foram avaliados quanto à densidade, motilidade e a proporção entre vivos e mortos, e a flora bacteriana em relação ao tipo predominante quando submetido à coloração de Gram, conforme descreve Dirksen (1993). A contagem de protozoários do fluído ruminal seguiu metodologia proposta por Dehority (1977).

As amostras foram analisadas nos dois momentos experimentais, comparando-os entre si, empregando-se para as variáveis $\mathrm{pH}$, TC e ATT, o método estatístico paramétrico "t" de Student. Para a análise das variáveis TSF, RAM, densidade, motilidade, porcentagem de infusórios vivos e contagem dos mesmos, foi empregado o método estatístico não paramétrico de Mann-Whitney conforme preconiza (Curi 1997), utilizando-se o programa de computador Statwinä (SigmaStat).

\section{RESULTADOS E DISCUSSÃO}

Nos achados obtidos foram encontradas diferenças nas variáveis estudadas, como pode ser observado nos Quadros 1, 2 e 3 , para os aspectos físicos, bioquímicos e microbiológicos.

No inverno a cor predominante foi a verde oliva em 32 amostras (64\%), seguida pela cor verde oliva escura em 15 amostras (30\%) de coloração mais intensa, lembrando a tonalidade do capim, e apenas 3 amostras (6\%) tenderam ao castanho, sendo denominadas pela cor verde oliva acastanhadas. No verão a disponibilidade de forragem foi bastante comprometida pela estiagem e o maturamento excessivo, havendo predomínio das nuances castanhas em 35 amostras (70\%) con-

\footnotetext{
${ }^{4}$ Potenciômetro - Corning ph-30.
}

Quadro 1. Aspectos físicos do fluído ruminal de ovinos Santa Inês criados extensivamente em Pernambuco

\begin{tabular}{lcc}
\hline Parâmetros do fluído ruminal & Inverno n (\%) & Verão n (\%) \\
\hline Cor & Verde-oliva & Castanho \\
& $32(64 \%)$ & $35(70 \%)$ \\
& Verde-oliva escuro & Verde-acastanhado \\
& $15(30 \%)$ & $14(28 \%)$ \\
& Verde-oliva acastanhado & Amarelo-palha \\
& $3(6 \%)$ & $1(2 \%)$ \\
Consistência & $1(2 \%)$ & $?$ \\
Moderadamente viscosa & $46(92 \%)$ & $32(64 \%)$ \\
Levemente viscosa & $3(6 \%)$ & $16(32 \%)$ \\
Levemente aquosa & $?$ & $2(4 \%)$ \\
Aquosa & $6,73^{\mathrm{a}} \pm 1,63$ & $3,15^{\mathrm{b}} \pm 0,72$ \\
Sedimentação e flotação (minuto)
\end{tabular}

Letras diferentes na mesma linha: $\mathrm{P}<0,05$.

Letras iguais na mesma linha: $\mathrm{P}>0,05$.

Quadro 2. Aspectos bioquímicos do fluído ruminal de ovinos Santa Inês criados extensivamente em Pernambuco

\begin{tabular}{lccc}
\hline $\begin{array}{c}\text { Parâmetros do } \\
\text { fluído ruminal }\end{array}$ & Unidade & Inverno & Verão \\
\hline $\mathrm{pH}$ & Grau & $6,76^{\mathrm{a}} \pm 0,21$ & $6,59^{\mathrm{b}} \pm 0,14$ \\
Azul de metileno & Minuto & $3,20^{\mathrm{a}} \pm 0,76$ & $7,76^{\mathrm{b}} \pm 3,00$ \\
Teor de cloretos & mEq/L & $28,14^{\mathrm{a}} \pm 4,16$ & $24,97^{\mathrm{b}} \pm 5,65$ \\
Acidez total titulável & $\mathrm{UC}$ & $21,90^{\mathrm{a}} \pm 4,38$ & $13,68^{\mathrm{b}} \pm 2,97$
\end{tabular}

Letras diferentes na mesma linha: $\mathrm{P}<0,05$.

Letras iguais na mesma linha: $\mathrm{P}>0,05$. 


\section{Quadro 3. Aspectos microbiológicos do fluído ruminal de ovinos Santa Inês criados extensivamente no Agreste Meridional de Pernambuco}

\begin{tabular}{lccc}
\hline $\begin{array}{l}\text { Parâmetros do } \\
\text { fluído ruminal }\end{array}$ & Unidade & Inverno & Verão \\
\hline $\begin{array}{l}\text { Protozoários } \\
\text { Densidade }\end{array}$ & + & $+++^{\mathrm{a}}$ & $++^{\mathrm{b}}$ \\
Motilidade & + & $++^{\mathrm{a}}$ & $++^{\mathrm{a}}$ \\
Vivos & $\%$ & $\sim 90^{\mathrm{a}}$ & $\sim 90^{\mathrm{a}}$ \\
Protozoários totais & $\mathrm{n}^{\circ} / \mathrm{mL}$ & $425373^{\mathrm{a}} \pm 217258$ & $155375^{\mathrm{b}} \pm 83113$ \\
Bactérias predominantes & & Gram-negativas & Gram-negativas
\end{tabular}

Letras diferentes na mesma linha: $\mathrm{P}<0,05$.

Letras iguais na mesma linha: $\mathrm{P}>0,05$.

\section{Quadro 4. Análise Bromatológica do capim-braquiária no} inverno e verão

\begin{tabular}{lcccccc}
\hline Parâmetro & MS (\%) & PB (\%) & FDN (\%) & FDA (\%) & EE (\%) & MM (\%) \\
\hline Inverno & 12,25 & 11,06 & 71,26 & 39,62 & 5,76 & 7,23 \\
Verão & 96,75 & 4,97 & 69,91 & 38,66 & 1,33 & 9,71
\end{tabular}

Quadro 5. Análise Bromatológica do capim-elefante no inverno e verão

\begin{tabular}{lcccccc}
\hline Parâmetro & MS (\%) & PB (\%) & FDN (\%) & FDA (\%) & EE (\%) & MM (\%) \\
\hline Inverno & 13,41 & 10,68 & 68,88 & 44,13 & 4,71 & 13,00 \\
Verão & 96,73 & 5,43 & 68,16 & 39,45 & 2,19 & 14,06
\end{tabular}

forme a tonalidade da pastagem, a qual era praticamente toda em cor de palha, havendo ainda 14 amostras (28\%) de cor verde acastanhada e uma amostra amarelo palha (2\%), estando de acordo com os achados de Souza (1990). A análise bromatológica das forragens ofertadas nos dois períodos experimentais está disposta nos Quadros 4 e 5.

$\mathrm{O}$ odor foi aromático em ambos os períodos experimentais, lembrando o tipo de alimentação ofertada, conforme descreve Dirksen (1993), mas a intensidade se mostrou mais forte no inverno, sendo uma mudança provavelmente relacionada à qualidade da pastagem, podendo também ser inerente à espécie, visto que Barbosa et al. (2003) analisando o fluído ruminal de bubalinos também encontraram odor mais pronunciado quando comparado ao odor do fluído ruminal em bovinos criados sob mesmo regime extensivo, mas não relacionaram os achados diretamente com a época do ano, pois estes autores analisaram o fluído ruminal apenas na estação chuvosa.

A consistência levemente viscosa predominou em ambas as estações. No inverno, foram encontradas 46 amostras (92\%) levemente viscosas, três $(6 \%)$ levemente aquosas e uma (2\%) moderadamente viscosa; já no verão apesar ter havido 32 amostras (64\%) levemente viscosas, constituindo a maior proporção, foram encontradas 16 amostras (32\%) levemente aquosas, número consideravelmente alto quando comparado ao inverno, havendo ainda 2 amostras (4\%) de consistência aquosa, estando as diferenças encontradas provavelmente relacionadas com a quantidade da microbiota e qualidade da forragem que variaram bastante entre os períodos experimentais, e possivelmente também com a ingestão de água e proporção da saliva presente no conteúdo ruminal (Silva et al.
1994) que difere conforme a espécie, apresentando-se mais viscosa em ovinos devido ao alto teor de mucoproteína (Hungate 1966). Estes achados corroboram com os encontrados por Garry (2002). Entretanto, analisando a consistência do fluído ruminal de ovinos e ruminantes selvagens Jones et al. (2001) descreveram ser menos viscosa nos primeiros.

O processo fermentativo avaliado pelo tempo de sedimentação e flotação (TSF) foi bastante favorecido na estação chuvosa, obtendo-se valor médio de 6,73 minutos $( \pm 1,63)$ para esta prova; já na estação seca, a baixa qualidade da pastagem comprometeu a fermentação de forma tal que poucas partículas flotaram e a sedimentação foi bem rápida com valor médio de 3,15 minutos $( \pm 0,72)$, formando-se uma fina camada de partículas alimentares, existindo diferença significativa $(P<0,05)$. Tais achados mostram a importância da qualidade do substrato alimentar na atividade microbiana, estando os valores relativos ao período de inverno dentro do limite preconizado por Dirksen (1993) em bovinos e acima dos valores encontrados por Feitosa (1991) para ovinos nas mesmas condições climáticas e de manejo. Porém, no verão a sedimentação foi mais rápida do que o tempo encontrado pelos autores supracitados.

Os valores médios de $\mathrm{pH}$ no inverno e verão foram de $6,76 \pm 0,21$ e $6,59 \pm 0,14$, respectivamente, sendo estes achados semelhantes aos obtidos por Feitosa (1991), havendo diferença estatística significativa $(p<0,05)$ entre os períodos experimentais, mas que do ponto de vista biológico não têm interferência na rotina de avaliação clínica, estando dentro do limite estabelecido para bovinos por Dirksen (1993).

A atividade microbiana avaliada pela RAM foi intensa no inverno com um tempo médio de 3,20 minutos $( \pm 0,76)$ quando comparada àquela do verão, onde o tempo médio foi de 7,76 minutos $( \pm 3,00)$, havendo diferença estatística $(P<0,05)$, com uma redução do corante em tempo,menor do que o citado por Dirksen (1993) para animais recebendo forragem. Entretanto foi semelhante ao tempo encontrado por Donato et al. (1999) em caprinos recebendo alimentação composta por $90 \%$ de capim-elefante e $10 \%$ de concentrado, o que provavelmente aconteceu devido aos altos níveis protéicos e a baixa percentagem de fibra favorecendo o crescimento e atividade microbiana no inverno, conforme descreve Van Soest (1994). No verão, a baixa qualidade do pasto, maturação excessiva e o alto teor de fibras comprometeram de forma clara a atividade da microbiota ruminal, que levou maior tempo para reduzir o azul de metileno, com os valores encontrados neste trabalho, acima dos observados por Feitosa (1991) e Silva et al. (1994) em ovinos e caprinos, respectivamente, sob mesmo manejo e dos constatados para bovinos por Garry (2002).

Os valores de cloreto encontrados no período chuvoso foram de $28,14 \mathrm{mEq} / \mathrm{L}$, estando acima dos registrados em bovinos por Dirksen (1993), que cita intervalo de valores médios entre $15-25 \mathrm{mEq} / \mathrm{L}$, refletindo provavelmente peculiaridades da espécie como o teor deste elemento na saliva, que de acordo com Garry (2002) apresenta valores semelhantes aos encontrados no flú́do ruminal, como pôde ser confirmado por Silva et al. (1994) estudando caprinos. No período seco o teor de cloretos foi de $24,97 \mathrm{mEq} / \mathrm{L}$, sendo menor quando com- 
parado ao período chuvoso, mas se manteve acima dos valores encontrados por Feitosa (1991), que foram de 16,71 e $19,25 \mathrm{mEq} / \mathrm{L}$ para ovinos das raças Merino Australiano e Corriedale, respectivamente, obtidos nas mesmas condições de manejo; refletindo provavelmente diferenças no consumo de sal mineral entre as estações, fator este também destacado por Braga (2005).

O valor médio da ATT, encontrado no período chuvoso, foi de $21,90 \pm 4,38$ UC e no período seco foi de 13,68 $\pm 2,97 \mathrm{UC}$, estando ambos dentro do limite mostrado para bovinos por Dirksen (1993), mas contrastando com as médias obtidas por Feitosa (1991) nos períodos chuvoso $(29,82 \pm 5,67$ UC) e seco $(26,76 \pm 4,92 \mathrm{UC})$ em trabalho com ovinos e os valores encontrados por Figueiredo et al (2000) analisando o fluído ruminal de caprinos, que foram de 30,4UC e 39,9UC nas respectivas épocas. Os resultados encontrados no presente trabalho foram menores em ambas às estações, refletindo provavelmente a menor qualidade do alimento disponível aos animais neste estudo.

A estimativa da quantidade de protozoários por campo microscópico mostrou densidade abundante no inverno $(+++)$ quando comparada à moderada encontrada no verão $(++)$, mas com boa quantidade de protozoários em ambos os períodos experimentais, havendo diferença estatística significativa $(\mathrm{P}<0,05)$ entre eles. Houve alta proporção de infusórios vivos em relação aos mortos, estando próxima de $90 \%$ e os mesmos apresentaram alta motilidade $(+++)$, não havendo diferença estatística significativa $(p>0,05)$ entre os períodos experimentais, estando os achados de acordo com os relatados por Dirksen (1993). A contagem de protozoários por mililitro de fluído ruminal foi bem maior no inverno (425.373 \pm 217.258$)$, com números aproximadamente três vezes maiores do que no verão $(155.375 \pm 83.113)$, havendo diferença estatística significativa $(\mathrm{p}<0,05)$ entre as estações, provavelmente estes achados ocorreram por haver melhor disponibilidade de substrato no primeiro, fator essencial para o crescimento adequado da fauna ruminal como elucida Hungate (1966).

O predomínio de bactérias Gram-negativas e a diversidade de formas encontrada em ambos os períodos experimentais corroboram com os relatos de Dirksen (1993) que descreve uma população de bactérias Gram-negativas predominando com grande diversidade de formas em animais recebendo volumoso. Houve maior densidade aparente das bactérias no inverno, com maior presença de pequenos cocos, bastonetes curtos e diversas cadeias de cocos Gram-negativos; já no grupo de bactérias Gram-positivas os tipos mais frequientes foram os grandes cocos e diplococos.

\section{CONCLUSÕES}

A estação do ano influenciou, de forma clara, as variáveis analisadas no fluído ruminal visto que a disponibilidade de forragem em quantidade e qualidade no período chuvoso promoveu uma ótima atividade da microbiota ruminal; o contrário pôde ser observado no período seco onde a maturação excessiva e a baixa qualidade do pasto comprometeram o metabo- lismo intra-ruminal, provocando diferenças na maioria dos parâmetros estudados. Sendo importante conhecer estas características para uma melhor avaliação do fluído ruminal nas diferentes épocas do ano e assim permitir um direcionamento adequado em relação ao melhor diagnóstico e tratamento dos diversos transtornos digestivos que acometem os ovinos.

\section{REFERÊNCIAS}

Andriguetto J.M., Perly L., Minardi I., Gemael A., Flemming J.S., Souza G.A. \& Filho A.B. 1999. Nutrição Animal. $3^{\underline{a}}$ ed. Nobel, São Paulo. 425p.

AOAC 1990. Official Methods of Analysis. Vol.1. 15th ed. Association of Official Analytical Chemistries, Arlington. 1117p.

Bacila M. 2003. Bioquímica do rúmen, p.167-181. In: Bacila M. (ed.), Bioquímica Veterinária. 2nd ed. Robe, São Paulo. 583p.

Barbosa J.D., Ávila S.C., Dias, R.V.C., Pfeifer I.B. \& Oliveira C.M.C. 2003. Estudo comparativo de algumas provas funcionais do fluido ruminal e de metabólitos sangüíneos de bovinos e bubalinos. Pesq. Vet. Bras. 23(1):3337.

Braga D.B.O., Almeida C.T., Kohayagawa A., Braga M.M. \& Berbari Neto F. 2005. Influência das estações de verão e inverno sobre os testes de digestão da celulose, sedimentação/flotação e conteúdo de cloretos em suco ruminal de bovinos. Hora Vet., Porto Alegre, 25(145):42-44.

Costa N.A. 1992. Estudo clínico do suco de rúmen de bovinos normais em diferentes manejos de arraçoamento com palma forrageira (Palma-gigante, Opuntia fícus indica) Mill. Dissertação de Mestrado, UFRPE, Recife. 57p.

Curi P.R. 1997. Metodologia e Análise da Pesquisa em Ciências Biológicas. Tipomic, Botucatu. 263p.

Dehority B.A. 1977. Classification and Morphology of Rumen Protozoa. Department of Animal Science, Ohio. 82p.

Dirksen G. 1993. Sistema digestivo, p.166-228. In: Dirksen G., Gründer H.D. \& Stöber M. (ed.), Rosenberger's Exame Clínico dos Bovinos. 3aㅗ ed. Guanabara Koogan, Rio de Janeiro. 419p.

Donato I.V., Soares P.C., Batista A.M.V., Silva E.P., Costa J.N., Marques C.T., Maya F.C.L. \& Teixeira M.N. 1999. Aspectos físico-químicos do fluído ruminal de caprinos recebendo dietas compostas de vagem de algarobeira (Prosopis juliflora) e capim elefante (Penisetum purpureum) em diferentes proporções. Ciênc. Vet. Tróp. 2(1):1-6.

Eads S. 1997. Physiology and pathophysiology of the rúmen. Proc. 15th Acvim Fórum, Lake Buena Vista, p.443.

Feitosa F.L.F. 1991. Avaliação do líquido ruminal em ovinos das raças Merino Australiano e Corriedale criados em regime extensivo de pastagem, no município de Botucatu-SP. Dissertação de Mestrado, Unesp, Botucatu. $88 \mathrm{p}$.

Figueiredo M.P., Quadros D.G. \& Cruz J.F. 2000. Acidez total titulável, pH e tempo de redução do azul de metileno no fluído ruminal de caprinos mantidos em pastagens artificiais exclusivas de gramíneas ou em caatinga. Braz. J. Vet. Res. Anim. Sci. 37(5). http://www.scielo.br/ scielo.php?script $=$ arttext\&pid $=$ S1413-95962000000500012\&In ...

Garry F.B. 2002. Simples indigestion, p.722-747. In: Smith B.P. (ed.), Large Animal Internal Medicine. 3rd ed. Mosby, St Louis. 1735p.

Hungate R.E. 1966. The rumen and its microbes. Academic Press, New York. 533p.

Jones R. J., Meyer J.H.F., Becas F. M., Stolz M.A., Palmer B. \& Van der Merwe G. 2001. Comparision of rumen fluid from South African game species and from sheep to digest tanniferous browse. Aust. J. Agric. Res. 52:453-460.

Miranda Neto E.G., Afonso J.A.B., Mendonça C.L. \& Almeida M.Z.P.R.B. 2005. Estudo clínico e características do suco ruminal de caprinos com acidose láctica induzida experimentalmente. Pesq. Vet. Bras. 25(2):73-78.

Rings D.M. \& Rings M.B. 1993. Rumen fluid analysis. Agric. Pract. 14(9):2629.

Silva H.K., Vianna L.G. \& Barbosa J.D. 1994. Provas funcionais do suco de 
rúmen de caprinos criados extensivamente na baixada fluminense. Pesq. Vet. Bras. 14(2/3):65-68.

Simplício A.A. \& Wander A.E. 2003. Organização e gestão da unidade produtiva. Anais V Congr. Pernamb. Med. Vet., Recife, PE.

Souza P.M. 1990. Conservação de suco de rúmen: avaliação das características microbiológicas e de determinadas provas funcionais. Dissertação de Mestrado, UFRPE, Recife. 87p.
Souza M.V. \& Barcellos A.R. 1993. Avaliação do fluido ruminal de bovinos e ovinos criados em regime de pastagem. Ciência Rural, Santa Maria, 23(1):31-36.

Van Soest J.P. 1994. Nutritional ecology of the ruminant. 2nd ed. Cornell University, New York. 476p.

Van Soest J.P., Robertson J.B. \& Lewi B.A. 1991. Methods for dietary fiber, neutral detergent fiber, and non starch polysaccharides in relation to animal nutrition. J. Dairy Sci. 74:3583-3597. 